\title{
ARTIGO
}

\section{TONS DE PELE: FLUXOS E FRICÇÕES}

\section{Denise Mancebo Zenicola}

Universidade Federal Fluminense

\section{RESUMO}

O presente artigo relaciona a presença de variados padrões estéticos, usuais na dança contemporânea, com certos poderes culturais hegemônicos utilizando conceitos de fluxo e fricção. O objetivo deste artigo é ressaltar o quanto elementos coreográficos podem apresentar de performance política na sua performance estética. Nosso eixo de análise temática remete, assim, aos conceitos e processos de hibridização, aculturação e assimilação presentes em Canclini, Gilroy e Louppe.

Palavras-chave: Performance. Dança contemporânea. Processos de criação. Transculturalidade. Performance política. 


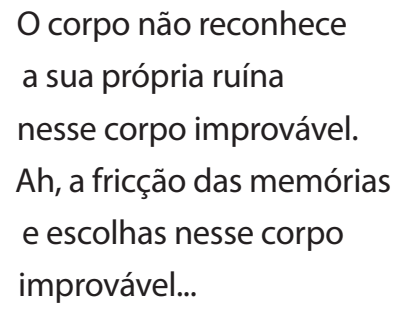

\section{Fluxos e contrafluxos}

$\Delta$ composição de elementos coreográficos, absorvidos de diferentes fontes e em diversos níveis de energia, revela-se no seu arranjo como uma prática recorrente na dança contemporânea. Tal fenômeno vem ocorrendo desde os anos 80 do século XX e, ainda na atualidade, mantém constantes níveis de inovação, embora se configure como já recursivo e solidificado na dança atual. Inúmeras são as causas e motivos apontados para a existência destas fusões: acusam os treinamentos por serem cada vez mais pontuais na formação do corpo do bailarino; o eterno caráter quase alquímico de experienciar sempre o novo em novas possibilidades com o corpo que dança; a fugacidade com que o tempo opera nas ações cotidianas contemporâneas, criando emergências pessoais; a ruptura com a visão linear da história da dança; como também a chamada perda das linhagens dos anos 1980.

Nos anos 1980 começa, no mundo da dança ocidental, em geral, uma mudança de paradigma do que se praticava até então nas escolas clássicas e depois nas chamadas modernas. Isto é, desenvolvia-se um estilo de criação, aprendizado e treinamento técnico que desembocava em um estilo coreográfico de dança próprio e definido como canônico. Logo, uma efetiva e longa formação técnica em uma determinada dança para a criação coreográfica que tinha uma clara identidade; a identidade do criador, o DNA do coreógrafo. Assim sendo, o corpo do bailarino construía-se de tal forma que se tornava um corpo reconhecível daquela prática estética e que se expressava, de forma claramente observável, através daquela determinada técnica de dança longamente apreendida. Segundo Louppe, era a "elaboração de um estado de corpo com um conjunto de princípios estéticos e filosóficos de um grande criador", um criador de espetáculo e corpos (2012, p. 31). Com a quebra deste padrão de formação, das chamadas "linhagens da dança", e como consequência prática deste conjunto de fatos, evidencia-se um outro modo particular de a obra se oferecer à nossa percepção. O que se observa na atualidade é a presença da criação de uma cultura em dança que prioriza constantes e visíveis alterações do discurso do corpo.

Nem sempre foram obtidos bons resultados no discurso deste corpo, afinal, com a presença de fusões em dança, algumas vezes, chega-se apenas a "motrizes justapostas" que, com assiduidade, alcançam "uma estranha maneira de deslizar corporeidades incompatíveis", num discurso corporal que, para muitos, pode chegar à beira da multiplicidade caótica (Louppe, 2000, p. 29). A proposital mistura de técnicas e gêneros artísticos advém do pluralismo de formas e estilos de pensar sobre o mundo, 
de concebê-lo, como também de o conformar em movimento. Com certo risco, o bailarino que visita diversos campos sem maior fixidez e/ou aprofundamento em cada um deles, ligando-se mais à estética do momento, pode originar na afoiteza um certo embaçamento no discurso desse corpo; como, com certo talento, o artista pode, por outro lado, alavancar voos inusitados em qualidade e expertise.

Cabe aqui refletir pontualmente sobre a chamada dança hibridizada contemporânea em relação à Obra de Arte Total, de Richard Wagner, Gesamtkunstwerk, pela não incidência de relações entre essas. A primeira trabalha com fusões mais específicas e direcionadas nos corpos e técnicas coreográficas, e a segunda, em fusões do espetáculo cênico a ser apresentado. Enquanto a primeira não tem maior compromisso com a tentativa de alcançar uma unidade e/ou harmonia, já a estética de Wagner propõe e exige profunda coerência das áreas das artes reunidas.

Compreende-se então que a combinação artística desta dança, chamada contemporânea, seja por contaminação, mistura, movimento, coerente ou não com a perspectiva de análise adotada, acontece em uma rede entrelaçada entre o local e o global. E, chamada de híbrida, relaciona-se mais com a reunião de elementos diversos para atingir a pluralidade das tramas e entrelaçamentos técnicos/estéticos, que esta diversidade pode provocar, do que servir à elaboração consciente e harmônica desses materiais. Tal fenômeno em dança, via de regra, visa provocar o contraste do improviso inusitado que pode chegar mais ao patamar da irreconciliável estranheza em um determinado universo coreográfico do que se obrigar a reconhecer ou mesmo conhecer as suas fontes e as suas ferramentas utilizadas, necessárias à leitura de sua própria diversidade. Este é um tema que abre questões imediatas, para maior compreensão da coexistência de técnicas múltiplas e encontros estéticos/culturais de aproximação na dança, pelos princípios de fluxo e fricções.

O falar de encontros e aproximações estéticos/culturais na dança nos remete à ideia de fluxo, que, segundo Hannerz (1997), indica uma natureza de prosseguimento, passagem e movência. $O$ bailarino contemporâneo atravessa artisticamente e com assiduidade fronteiras, tanto no limite local de um lugar para outro, num determinado tempo, "ligado a uma questão territorial, como também na dimensão temporal sem implicações espaciais necessárias" (Hannerz, 1997, p. 11). E, nesse fluxo constante, a dança pode obter ampla multicentralidade de fluxos e contrafluxos, e alargar suas possibilidades de encontros, como, por exemplo, os encontros de eixos verticais da dança clássica com os eixos lateralizados dos apoios africanos o que vai assumir um interessante pluralismo de olhares e resultados, ao se considerar as resultantes de tais fluxos entrecruzados.

O conceito de fluxo na dança em si é bastante amplo e dotado de um denso lastro, uma vez que os processos transformadores da cultura na dança, ou seja, suas dinâmicas culturais, são articulados aos fluxos do mundo contemporâneo em que esta dança circula e dialoga. Em meio a esse curso, entre a aproximação dos "objetos" diversos e dissimiles (pessoas, artefatos propriamente ditos, ideias, valores), temos, na maioria das vezes, a produção de um terceiro "objeto", o sociocultural. A esses procedimentos socioculturais, nos quais arcabouços ou práticas diversas que existiam de uma determinada forma se cruzam e determinam outras práticas distintas, Canclini (2006) indica como hibridação. 


\section{Peles híbridas e fricções}

A imagem da "pele híbrida" vai nos levar a categorias de pensamento, do falar da diferença, do Eu e o Outro, bem como de mestiçagem cogitada como cruzamento entre as raças/etnias e de sincretismo, mais associada à relação entre as religiões, isto é, todos conceitos que se encontram vinculados entre si e também são constantemente confrontados.

Como esperado, as linhas de delimitação entre os três modelos - hibridismo, mestiçagem e sincretismo - são próprias e porosas, afinal, estes são elementos correlatos de síntese biológica, cultural, espiritual e política, gerados em consequência de determinados processos de atravessamento de fronteiras. No entanto, não se pode negar que os três padrões, nas suas mais variadas possibilidades de intensidade e adensamento, levam ao desenraizamento do corpo, uma vez que suspendem sua zona de conforto cultural e desalinham certezas antigas para novos realinhamentos.

O termo "hibridação" foi escolhido por Canclini, ao invés de sincretismo" ou mestiçagem ${ }^{2}$, porque, para o autor, hibridismo é o conceito que melhor esclarece o envolvimento das fusões contemporâneas de forma geral, como "processos tecnológicos, migratórios e econômicos, enquanto que os demais termos se restringem a campos religiosos e étnicos", respectivamente; logo, para indicar tais artes de composição, o conceito do híbrido alcança um número maior de mesclas transculturais. Trataremos especificamente deste aspecto adiante (Canclini, 2006, p. 19).

É importante ressaltar que o hibridismo dançado é algo de certa forma previsível e que faz parte das concepções culturais, em seu caminho natural, desde que nascem e à medida que vão evoluindo e mudando ao longo do tempo e do espaço. Na verdade, misturar é um fazer humano e artístico natural, e o que se questiona na arte dançada parece, por vezes, mais um saudosismo do tempo dos grandes criadores e das consagradas escolas de dança e seus repertórios canônicos.

Como estética híbrida e refletindo nossa análise especificamente para a dança, esta apresenta-se, como nos estudos culturais, por meio de três modelos (Williams,1981, p. 89). O primeiro pode ser abalizado enquanto modelo de "hibridismo por fusão" de elementos, nascido da combinação de práticas de movimentos em que a dança será inteiramente nova e perfeitamente distinta das anteriores, como é a dança-teatro de Pina Bausch, que alcança a coerência dos materiais reunidos,

\footnotetext{
1 Para Canclini (2006, p. 19), o conceito de sincretismo refere-se, via de regra, a fusões religiosas ou de movimentos simbólicos tradicionais.

2 Mestiçagem, para Gruzinski (2001, p. 62), designa misturas que ocorreram nas Américas no século XVI entre seres humanos, campos simbólicos, imaginários e práticas de vida, vindos de outros povos da Europa, África e Ásia. "As mestiçagens nunca são uma panaceia; elas expressam combates jamais ganhos e sempre recomeçados" (Gruzinski, 2001, p. 320).
} 
de dança e teatro fusionados através da dramaturgia do corpo ${ }^{3}$, seja a partir das técnicas pessoais previamente adquiridas dos bailarinos, seja na aliança corporal sensível e ideológica dos bailarinos com suas memórias. O segundo modelo, "hibridismo por interpenetração", alia subsídios e técnicas de danças em diferentes formas e graus, mas que não se fusionam totalmente e são prontamente identificáveis, tal como a dança de Louise Lecavalier, que interpenetra dança clássica, pirouettes en dehors ${ }^{4}$, entrechat quatres ${ }^{5}$ com rolamentos acrobáticos, suportes e alavancas de dança contemporânea, mas que se mantêm reconhecivelmente distintas, por parte do olhar educado.

O terceiro modelo é o que questiona a noção de diferença apresentada nos dois exemplos anteriores, que mescla o "híbrido por fusão" com o "híbrido por interpenetração" ora utilizando-se de um, ora do outro, numa mesma obra coreográfica, criando as mais inusitadas e arrojadas possibilidades, o que é feito com excelência por Akram Khan na obra Sacred Monsters, em parceria com Sylvie Guillem.

Estes processos alcançam ainda novos contornos e olhares, quando entendemos as formas de apropriação ou aculturação presentes nestes fazeres alquímicos. A dança contemporânea apresenta-se como algo ainda chamado de inovador e transgressivo, como força fecunda, capaz de agitar, desnaturalizar e até mesmo desestabilizar concepções canônicas e hegemônicas na dança. Nesse sentido, um olhar bastante peculiar é o de Philippe Decouflé, que desenvolve coreograficamente "figuras polimorfas imaginadas que participam ao mesmo tempo do mundo animal, mineral e vegetal", num destino do corpo que altera sua estética em imagem (Louppe, 2012, p. 36).

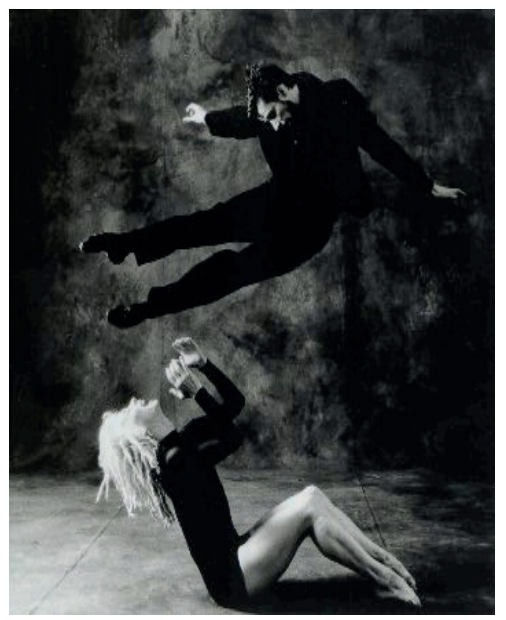

Figura 1. Louise Lecavalier, de La La La Human Steps, de Sarah Elgart.

\footnotetext{
3 "Segundo Pavis (1999, p. 113), dramaturgia, no seu sentido mais genérico, é a técnica ou a poética da arte dramática que procura estabelecer os princípios de construção da obra". E, no sentido brechtiano e pós-brechtiano, "dramaturgia é ao mesmo tempo ideológica e formal da peça" (Brecht apud Pavis, 1999, p. 113). Alargamos aqui este conceito para as ações do corpo, enquanto sua inerente capacidade de contar histórias ao expor, criar nós temáticos, apresentar conflitos, concluir ideais e finalizar a história contada.

4 Trata-se de um tipo de giro em torno do eixo do bailarino, específico da técnica da dança clássica.

5 Um passo no qual o bailarino pula no ar e cruza rapidamente as pernas atrás uma da outra. Existe o entrechat deux (um cruzamento), quatre (dois cruzamentos), six (o pé da frente bate uma vez no ar no pé de trás e cai trocando os pés), cinq (igual ao quatre, porém a caída é sobre um pé, sendo que o outro fica sur le cou-de-pied), trois e sept (igual ao six, mas a descida é sobre um pé, sendo que o outro é sur le coude-pied). Disponível em: https://danca.wordpress.com/tag/dicionario-de-ballet.
} 


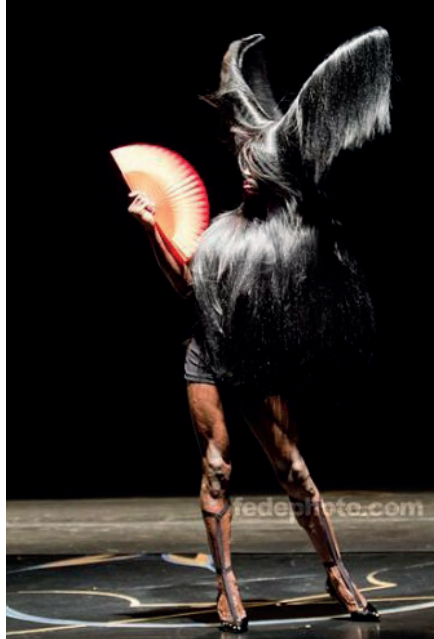

Figura 2. De La_Villette, direção de Philippe Decouflé.
Esta pretensa, ainda jovem e não esgotada linguagem de dança aponta para que, se antes o bailarino cedia à figura do criador/encenador e/ou do coreógrafo ${ }^{6}$ tradicional, sem esta figura, que o conduzia e pensava o conceito artístico e o traduzia em técnica de dança e/ou coreográfica, agora ele, o artista ${ }^{7}$, pode caminhar sozinho. Se antes seguia um caminho predefinido pelo coreógrafo tradicional, que utilizava o serviço do ensaiador ${ }^{8}$, ele agora pode estar e agir só, caso queira. Logo, tal liberdade aponta para mais decisões estéticas, isto é, ou o artista segue as correntes estéticas de dança já existentes, escolhe a tradição negando a possibilidade híbrida, ou rompe com as correntes tradicionais e se hibridiza.

Se hibridiza-se aleatoriamente, por falta de conceito, corre o risco de perder-se no processo político da ação e tornar-se mercadológico e/ou vazio de conteúdo artístico cultural, mesmo que alcance alto índice técnico em eficácia do movimento dançado. $\mathrm{E}$, se quer escolher, tem que aprender a criar o seu próprio conceito artístico, seu repertório, procurar o seu lugar, o que lhe cabe ser e o que quer fazer, tem que criar a sua estética alquímica, suas escolhas, sua pegada no mundo.

E, para esses últimos, os que optam por fazer suas próprias escolhas, é preciso cogitar ainda o quanto este fazer cabe realmente ao performer/bailarino, num circuito individual e bastante autorreferente, apoiado na sua capacidade pessoal de se construir como ser pensante da sua estética, da sua cultura, da sua tradição para aquisição consciente de suas ferramentas simbólicas.

Não há dúvida de que o performer/bailarino, o que se constrói a partir de seus conhecimentos e sínteses, alimenta suas escolhas estéticas. Isso é fato. E aqui citamos o exemplar trajeto do estudo antropológico praticado na dança, enquanto forma de cultura, por Akram Khan, inglês de ascendência bangladeshiana.

\footnotetext{
6 Citamos aqui o criador/encenador como o trabalho exercido pelo coreógrafo, que é o responsável pela produção do movimento e pela direção da montagem do trabalho de coreografia. Entendendo-se uma

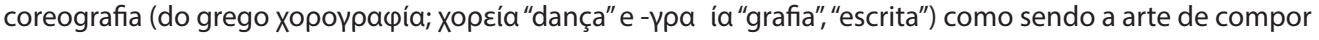
trilhas e/ou o roteiro de movimentos que compõem uma dança.

7 Aqui chamamos de forma geral "o artista", mas cabe nessa categoria o bailarino, como também o coreógrafo que assume o rompimento com as chamadas grandes escolas e linhagens de dança e passa a praticar tais princípios e fusões na dança.

8 O ensaiador é o profissional que executa o trabalho de repassar determinada obra coreográfica, sob a direção do coreógrafo presente ou não, e age principalmente em ballets chamados de repertório, obras canonizadas e que são estudadas e repetidas, respeitando-se a total fidelidade da obra.
} 
A sua capacidade de atribuir uma natureza cultural construída no movimento dançado desenvolve e revela conhecimento sobre o seu mundo. Nesse caso, o produto coreográfico é uma performance do conhecimento de si, o que, segundo Clifford Geertz, "um metacomentário que o artista faz sobre a sua própria vida" 9 (Geertz, 1989, p. 448). Sua dança expressa o poder de uma tradição na qual a autobiografia se torna um ato ou processo de simultânea autocriação e autoemancipação. Seus modelos e significados culturais postos em ação colaboram para a formulação e instauração de seus próprios valores ao fusionar primeiro danças folclóricas indianas e, depois, dança clássica, estilo kathak, e dança contemporânea ocidental.

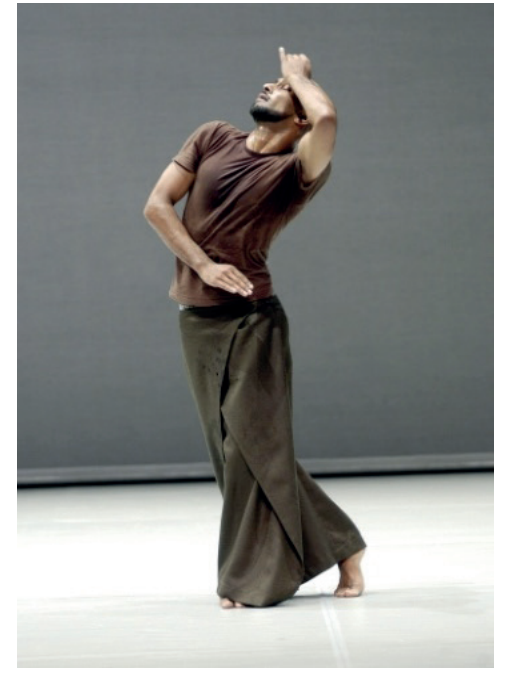

Figura 3. Akram Khan em Zero Degrees (foto de Jean-Pierre Maurin).

A descrição que Khan faz do seu processo de aprendizagem de vários "idiomas" da dança e do modo como, a partir deles, inventa uma nova linguagem, é um exemplo da forma como individual e criativamente as práticas e os habitus são permanentemente reconfigurados e reinventados, a partir dos cânones transmitidos e experiências vividas. Khan explica que com a dança contemporânea os seus olhos "abriram-se a um mundo totalmente diferente, de diferentes formas de nos expressarmos". Porém, à medida que ia desenvolvendo o seu trabalho em torno da dança contemporânea, o seu corpo "was getting confused" [...] tal como é reconhecido pelo próprio criador, o seu trabalho baseia-se na pesquisa de uma linguagem de movimento singular, no encontro de um estilo próprio que tem como núcleo o trabalho dos braços, a velocidade e a fluidez do movimento e o controlo do ritmo - características do estilo de dança do norte da Índia de que Akram Khan é um exímio intérprete". (FAZENDA, 2010, p. 8).

No entanto, há mais e outros envolvimentos e escolhas na construção deste corpo que é atravessado pela cultura coreográfica: é o fato de que sempre se deve estar atento de quais culturas quer fazer parte, quais culturas quer assumir como sua. Isto é, quais estruturas transnacionais existentes na modernidade são escoIhidas, sejam estas técnicas globais ou locais em seus respectivos fluxos, fusões e trocas culturais. Por outro lado, este híbrido construído relaciona-se também, e bastante, com um desaparelhamento cultural, isto é, este corpo pode acabar escolhendo pouco, se ele de alguma forma é escolhido quando se submete ou é submetido às leis do mercado e, principalmente, à culturas de danças hegemô-

9 Original: "a story they tell themselves about themselves". 
nicas estrangeiras de si e pode resultar por ocorrer uma negação da sua própria herança. Esse corpo, que no fundo pouco escolheu, pode, sem perceber, negar as conquistas do corpo na ideologia e história, e caminhar de forma, nem sempre consciente, para o sonho de uma dança sem origens. Uma dança que, pela própria ocultação de sua história, mesmo que perfeita tecnicamente, apresenta um quê de embaçamento de vida.

Talvez seja por isso que a estética híbrida dançada apresente algo que range, que parece não funcionar direito, que fricciona, ora seja porque a dança híbrida estabelece-se na ruptura das fronteiras, ora por ter a concepção espaço temporal alterada, ou mesmo seja porque fala de uma não pertença cultural, e assim vai sugerir a presença de um escasso e instável equilíbrio de forças e de falta de consonância quanto à harmonia do seu produto final. Um desconforto deslocado do corpo que não se constitui a partir de uma consciência contínua ou harmônica de si.

A pluralidade das tramas culturais, fenômeno natural da mundialização, quando excede certos parâmetros, invade e põe em risco a lenta e natural impregnação epidérmica, necessária para o sentido de pertencimento que a dança precisa adquirir para ser verdade no corpo. O ponto significante a ser considerado aqui é que, longe de ser uma composição harmônica de diferenças, o termo hibridação na antropologia, via de regra, também é empregado em processos e procedimentos "violentos" de encontros e cruzamentos culturais (Gruzinski, 2001, p. 62).

Existem linhas de pensamento que rejeitam atribuir ao hibridismo uma posição política, independentemente se ela é boa ou má, e assim fazem uma leitura histórica e geográfica deste fenômeno, analisando, em limitado recorte fechado, os intrincados jeitos, como se fosse um "não poder" que se circula na realidade dançada. Há outras linhas de pensamento que não negam o político, mas mantêm a aceitação segundo a qual o hibridismo constitui um contorno de oposição às supremacias de toda a natureza, eclipsando assim as efetivas relações de poder preexistentes, uma contracultura do poder em que, ao se hibridizar, some o comando. Mas, do que tratamos aqui, o dançar, não é só uma questão do corpo ser atravessado ou não por diversas correntes, e sim que devemos identificar quais são essas correntes: se são políticas que submetem, se são políticas inovadoras de anulação das hegemonias, se são tentativas apolíticas ou apenas a escolha de seguir este ou aquele ato criador, sem pretender efetuar hibridizações.

No Brasil, mesmo com o crescente número de grupos de pesquisa em danças, existe ainda uma primazia, embora cada vez menos acentuada, das danças eurocêntricas e/ou americanas que permanecem ou ainda tentam permanecer no domínio dos conceitos modernos, enraizados em suas categorias, experiências e subjetividades. Isto é, o tal hibridismo está em exponencial crescente e cada vez menos representado pelas danças clássicas. Mesmo assim, ainda se escuta o discurso da grande subserviência às chamadas danças clássicas através da máxima "quem dança ballet, dança qualquer dança" - claro, um discurso alimentado a preços não tão módicos em escolas especializadas de ballet. 
Será este peso em desequilíbrio para determinado lado, algo inevitável e previsível, que faz parte absolutamente integrante das formações culturais hegemônicas no seu habitual trajeto de poder? $\mathrm{E}$, ao não se estar atento a esse desequilíbrio, corre-se o risco de cair em um utopismo romântico e achar que este movimento de descolonização na dança presente, desde que se constituiu, nos dá uma sensação de que, unindo, todos nos fortaleceremos e seremos iguais?

É grandeza particular dos privilegiados e destino imperativo dos carentes de poder a aceitação da relação centro-periferia, Primeiro e Terceiro Mundos, o eu e o outro? Mas também é certo que, à medida que o centro de poder na dança for evoluindo e mudando, ao longo do tempo e do espaço, novas realidades realmente transformadoras e complexas surgirão.

\section{Concluindo sempre provisoriamente}

Seja "híbrido por fusão", "híbrido por interpenetração”, amalgamado ou justaposto, o movimento híbrido dançado, no nascimento dos gestos, está sempre em constante mistura do eternamente misturado e aponta que cruzamentos divergentes revelam novos materiais em perdas e ganhos.

$\mathrm{Na}$ oportunidade de discutir o complexo entrelaçamento, cabe-nos refletir qual estética ou estéticas de poder atravessam o corpo que dança e vão elencando vários tipos de estilos até chegar a um princípio "étnico-transcultural".

Quem se beneficia, de forma recíproca ou unilateral, com esse sonho de uma dança sem origens, se é que existe uma dança sem origem?

Como o ato coreografado, sem fronteiras, que admite a globalização como processo irreversível, mas que quer garantir a identidade de culturas expressivas, como as do Oriente Médio e da África, por exemplo, pode estabelecer estruturas coreográficas vinculadas a partir de pequenas partes e em constantes reconstruções?

O que está por trás do ato coreografado étnico transcultural e multifacetado, resistência ou aceitação, verdadeiro caldeirão de inovação ou continuísmo?

O hibridismo resulta de uma qualquer forma de dominação, o que se quer falar, de que forma e de qual lugar se fala o que se fala?

O que se defende e expõe ou se nega e, portanto, invisibiliza, o que se quer lembrar, o que se quer esquecer?

Fica sempre a dúvida se o hibridismo é imposto ou é assumido e, nesses pesares, constitui-se por natureza regressivo ou ato revolucionário, uma vez que há sempre a percepção segundo a qual o hibridismo resulta de uma forma de dominação colonizadora. Se é assim, hibridiza, mas fica no comando, aproxima apenas para oxigenar o velho e gasto, tal como uma nova fórmula de lucrar com a venda do outro chamado exótico. Será?

Claramente temos amplas questões para refletir a dança contemporânea quando se dá maior atenção e respeito aos valores que a regem, suas possíveis linhagens na ética e escolhas feitas, afinal, a poética dançada apoia coragens, remetendo mais uma vez à noção de identidade. 
Ao princípio de fricção, de espaço intermediário, campo de abandono ou produtor de novas formas artísticas, há algo que "range", que parece não funcionar direito, que resultaria em um caos efêmero ou até mesmo duradouro.

Frente às delimitações, fusões, interpenetrações, reciclagens, mixagens de culturas, via de regra díspares, a construção constante estabelece sucessivas regenerações de dança.

O que se percebe, num decorrer um pouco paradoxal, é que a fricção tira a sua vitalidade, num certo sentido, das suas próprias fendas, ruínas e escombros, e nos faz perceber que quase sempre há um peso em desequilíbrio, pendendo para determinado lado, nos encontros com as diversas artes e culturas.

É preciso refletir as qualidades relacionais desta dança, com os seus conflitos e fricções, e, antes de delimitar estéticas, urge delimitar o lugar que a arte ocupa dentro do nosso imaginário político-ideológico. Mais ainda, uma vez que esta dança aparece como um lócus estratégico de interlocução, é preciso perceber se esta realmente cumpre com justeza o seu real e necessário papel dentro do nosso imaginário. Aí, sim, teremos uma força no corpo que exale vida em seus múltiplos e possíveis tons de pele.

Ah, a fricção das memórias e o ranger das escolhas nesse corpo improvável...

\section{REFERÊNCIAS}

CANCLINI, Néstor Garcia. Culturas Híbridas: estratégias para entrar e sair da modernidade. 4. ed. São Paulo: EDUSP, 2006.

DANÇA. Dicionário de ballet. Disponível em: https://danca.wordpress.com/tag/ dicionario-de-ballet. Acesso em: 31 ago. 2018

FAZENDA, Maria José. As histórias que as pessoas dançam sobre si próprias: as linguagens de Jérôme Bel, Montalvo/Hervieu, Shobana Jeyasingh e Akram Khan. Lisboa: Instituto Politécnico de Lisboa, 2010. Disponível em: http://hdl.handle. net/10400.21/2580.

GEERTZ, Clifford. A Interpretação das Culturas. Rio de Janeiro: LTC,1989.

GRUZINSKI, Serge. O pensamento mestiço. São Paulo: Companhia das Letras, 2001. HANNERZ, Ulf. Fluxos, Fronteira, Híbridos: Palavras-chave da antropologia transnacional. Revista Mana, Rio de Janeiro, v. 3, n. 1, 1997.

LOUPPE, Laurence. Poética da Dança Contemporânea. Lisboa: Orfeu Negro, 2012. LOUPPE, Laurence. Corpos Híbridos. In: PEREIRA, Roberto. Lições de dança 2. Rio de Janeiro: UniverCidade Editora,2000.

PAVIS, Patrice. Dicionário de Teatro. Tradução de Jacob Guinsburg e Maria Lúcia Pereira. São Paulo: Perspectiva, 1999.

WILLIAMS, Raymond. Sociología de la cultura. Tradución de Graziella Baravalle. Supervisión de M. Gracia Cantó. Fontana: Paidós, 1981. 